\title{
Meta-Analysis of a Web-Based Disease Forecast System for Control of Anthracnose and Botrytis Fruit Rots of Strawberry in Southeastern United States
}

\author{
Leandro G. Cordova, Gulf Coast Research and Education Center (GCREC-UF), University of Florida, Wimauma 33598; Laurence \\ V. Madden, Department of Plant Pathology, The Ohio State University, Wooster 44691; Achour Amiri, Tree Fruit Research and Extension \\ Center, Washington State University, Wenatchee 98801; Guido Schnabel, School of Agricultural, Forestry \& Life Sciences, Clemson Uni-
} versity, Clemson, SC 29634; and Natalia A. Peres, ${ }^{\dagger}$ GCREC-UF, University of Florida, Wimauma 33598

\begin{abstract}
Strawberry production in Florida and South Carolina is affected by two major diseases, anthracnose fruit rot (AFR) and Botrytis fruit rot (BFR), caused by Colletotrichum acutatum and Botrytis cinerea, respectively. The effective management of both diseases traditionally relied on weekly fungicide applications. However, to improve timing and reduce the number of fungicide sprays, many growers follow the Strawberry Advisory System (StAS), a decision support system for forecasting fungicide applications based on environmental conditions and previously developed models. The objective of this study was to perform a meta-analysis to determine the effectiveness of the StAS for AFR and BFR management compared with a calendar-based spray program. Thirty-nine trials were conducted from 2009 to 2014 in Florida and South Carolina commercial

strawberry fields. Meta-analysis was conducted to quantify the treatment effects on four effect sizes, all based on the difference in response variables for StAS and the calendar-based treatments in each trial. The mean difference in BFR incidence, AFR incidence, yield, and number of marketable fruit between the two treatments was not significantly different from $0(P<0.05)$. However, the number of fungicide applications per season was reduced by a median of seven when using the StAS, a $50 \%$ reduction in sprays compared with the calendar-based approach. Effect sizes were not influenced by location or the favorability of the environment for disease development. These findings indicate that use of StAS in commercial fields is effective in controlling fruit rot diseases with no reduction in yield while substantially reducing fungicide applications.
\end{abstract}

The two major pathogens affecting strawberry production in the southeastern United States are Colletotrichum acutatum and Botrytis cinerea, the causal agents of anthracnose fruit rot (AFR) and Botrytis fruit rot (BFR), respectively. In Florida, the combination of optimum temperatures and high precipitation, especially during El Niño years, may significantly increase the incidence of fruit rots (Fraisse et al. 2006; Pavan et al. 2011).

During periods when weather conditions are conducive for BFR development ( $>12 \mathrm{~h}$ of leaf wetness and temperatures from 15 to $25^{\circ} \mathrm{C}$ ) (Bulger et al. 1987; MacKenzie and Peres 2012a), strawberry yields can be reduced by more than $50 \%$ even if a scheduled fungicide program is followed (Ellis and Grove 1982; Legard et al. 2001; Mertely et al. 2002). In the southeastern United States, BFR is traditionally managed using a calendar-based program in which multisite fungicides such as captan or thiram are sprayed weekly regardless the presence of flowers. However, if during bloom the weather conditions are favorable for BFR development, a single-site fungicide such as fenhexamid, pyrimethanil, pyraclostrobin + boscalid, or cyprodinil + fludioxonil is recommended (Legard et al. 2005; MacKenzie and Peres 2012a; Mertely et al. 2009).

AFR affects mainly flowers and fruit, causing yield losses that can also exceed 50\% even in well-managed crops (Howard et al. 1992; Turechek et al. 2006). Management of AFR relies on the integration of cultural practices, resistant cultivars, and fungicide sprays. The best way to manage the disease is to prevent the entrance of the pathogen into commercial fields by planting pathogen-free transplants. However, transplants with quiescent infections can be moved to production fields unnoticed and serve as sources of inoculum (Peres et al. 2005). The use of partially resistant cultivars is a good disease-management tool, but those cultivars may not be adopted if they are not the most productive or have the best quality (Chandler et al. 2006; Seijo et al. 2008). Therefore, the most common and reliable management tool is the use of preventive fungicide sprays throughout the season. Traditionally, protectant

${ }^{\dagger}$ Corresponding author. E-mail: nperes@ufl.edu

Accepted for publication 15 June 2017.

@ 2017 The American Phytopathological Society fungicides such as captan are applied weekly during the strawberry season in Florida, and partially systemic products such as pyraclostrobin, azoxystrobin, or the mixture of cyprodinil and fludioxonil are applied when environmental conditions are highly conducive for disease development ( $>12 \mathrm{~h}$ of leaf wetness and temperatures from 15 to $30^{\circ} \mathrm{C}$ ) and the crop is in bloom (MacKenzie and Peres 2012a; Peres et al. 2010; Wilson et al. 1990).

The large number of calendar-based fungicide applications during a season, the high sensitivity of AFR and BFR to environmental conditions, and the daily variation in weather conditions within and between seasons all suggest that these two diseases are good candidates for disease forecasting or prediction. Forecasting has a long history in plant pathology (Campbell and Madden 1990; De Wolf and Isard 2007), and many prediction models have been developed over the past century or more. However, developed prediction models are not used commercially, even when accuracy is high (McRoberts et al. 2011; Shtienberg 2013). One historical reason for low acceptance by growers is the time and labor costs of maintaining environmental monitoring equipment within fields and in running models either manually or on computers. Advances in remote estimation of local environmental conditions, server-based processing of environmental data, and delivery of forecasts (with explanatory material) over the Web, e-mail, or short message service (SMS) have opened up new opportunities for real-time disease forecasting (DeWolf and Isard 2007; Gent et al. 2013).

The Strawberry Advisory System (StAS) was released in Florida in the 2009-2010 cropping season to advise growers to apply fungicides only when environmental conditions are favorable for either AFR or BFR. StAS is a web-based system that predicts AFR and BFR outbreaks by calculating a disease incidence index score based on leaf wetness duration (LWD) and mean temperature during the wetness period (Pavan et al. 2011). The models used for StAS were based on previous work on the relationship of LWD and temperature for BFR (Bulger et al. 1987) and for AFR (Wilson et al. 1990) development. The risk of disease development is classified in three categories (low, moderate, or high risk) depending on the calculated index score and on the thresholds determined by MacKenzie and Peres (2012a; 2012b) for each disease. Whenever these thresholds are reached, an SMS and/or e-mail alert is sent to subscribers to the system indicating that it is time to spray for either AFR or BFR (Pavan et al. 2011). A mobile app version of StAS has also been developed recently (Fraisse et al. 2015). 
The adoption of new technologies by growers is challenging, especially in strawberry due to the high value of the crop. After being evaluated and validated by the developers, a system needs to be tested by potential users in realistic situations (Magarey et al. 2002). In addition to being accurate, a forecasting advisory system must also be costeffective in the long term and practical to use (Gent et al. 2013; McRoberts et al. 2011). To be validated, results should be obtained from trials conducted in different locations for several years. Metaanalysis combines results from multiple studies and evaluates the effect of treatments or the relationship between variables. The outcome of each study represents a single observation in meta-analysis of the complete set of studies (Madden and Paul 2011; Paul et al. 2011; Piepho et al. 2012). The popularity of meta-analysis increased significantly in the past few years as proven by the many studies relying on it in several pathosystems (Dalla Lana et al. 2015; Komatsu and Kondo 2015; Madden et al. 2016; Ngugi et al. 2011; Paul et al. 2005; Paul et al. 2008; Paul et al. 2011; Salam et al. 2013; Scherm et al. 2014; Willyerd et al. 2012).

The objective of this study was to perform a meta-analysis of 39 trials conducted from 2009 to 2014 in Florida and South Carolina to determine the effectiveness of the StAS for managing the fruit rot diseases of strawberry. The field trials were carried out on commercial farms and the results on disease incidence and yield (marketable fruit number and fruit weight) compared for calendar-based fungicide applications and fungicide applications following the StAS recommendations. Through the meta-analyses, we could estimate both the mean effectiveness of the StAS as well as the variability of the predictor efficacy, and, through a moderator-variable analysis, determine which if any trial-level factors influenced the effectiveness of the system.

\section{Materials and Methods}

Data collection. A total of 39 field trials were conducted during five consecutive strawberry seasons (2009-2010 to 2013-2014) in Florida and South Carolina. Trials were established in 11 commercial fields in Balm, Dover, Floral City, and Plant City in Florida, and four commercial farms in Kiesler and Bob Hall in South Carolina (Table 1). Eight cultivars (Strawberry Festival, Alafia, Sanibel, Treasure, Camarosa, Radiance, Albion, and Winterstar) from at least 13 different nurseries were used in these trials (Table 1).

Each field was prepared in late-August to early-September of each year by growers following local production standards. Transplants were planted between late-September and mid-October and were

Table 1. Geographic location of strawberry fields, cultivars, nurseries, and number of fungicide applications of 39 trials conducted throughout five strawberry seasons

\begin{tabular}{|c|c|c|c|c|c|c|}
\hline \multirow[b]{2}{*}{ Season } & \multirow[b]{2}{*}{ Location/State $^{\mathrm{a}}$} & \multirow[b]{2}{*}{ Commercial field $^{b}$} & \multirow[b]{2}{*}{ Cultivar } & \multirow[b]{2}{*}{ Originating nursery ${ }^{\mathrm{c}}$} & \multicolumn{2}{|c|}{$\begin{array}{l}\text { Number of fungicide } \\
\text { applications }\end{array}$} \\
\hline & & & & & Calendar & $\overline{\text { StAS }}$ \\
\hline \multirow[t]{6}{*}{$2009-2010$} & Dover/FL & BB & StrawberryFestival & $\mathrm{n} 3$ & 9 & 2 \\
\hline & & $\mathrm{PF}$ & Alafia & $\mathrm{n} 4$ & 7 & 3 \\
\hline & & & Sanibel & $\mathrm{n} 4$ & 9 & 4 \\
\hline & Plant City/FL & $\mathrm{FF}$ & Treasure & $\mathrm{n} 2$ & 14 & 4 \\
\hline & & & & $\mathrm{n} 7$ & 14 & 4 \\
\hline & & & & $\mathrm{n} 8$ & 11 & 3 \\
\hline \multirow[t]{7}{*}{ 2010-2011 } & Dover/FL & $\mathrm{BB}$ & Festival & $\mathrm{n} 8$ & 11 & 6 \\
\hline & & $\mathrm{PF}$ & Alafia & $\mathrm{n} 4$ & 11 & 4 \\
\hline & & $\mathrm{S}$ & Festival & $\mathrm{n} 8$ & 11 & 6 \\
\hline & Plant City/FL & FF & Festival & $\mathrm{n} 7$ & 9 & 4 \\
\hline & & & & $\mathrm{n} 8$ & 11 & 4 \\
\hline & & & & n9 & 8 & 3 \\
\hline & Lexington/SC & $\mathrm{K}$ & Camarosa & $\mathrm{n} 10$ & 13 & 6 \\
\hline \multirow[t]{13}{*}{ 2011-2012 } & Balm/FL & $\mathrm{Be}$ & Radiance & $\mathrm{n} 12$ & 12 & 3 \\
\hline & Plant City/FL & FF & Festival & $\mathrm{n} 7$ & 14 & 6 \\
\hline & & & Radiance & $\mathrm{n} 1$ & 14 & 6 \\
\hline & & & & $\mathrm{n} 11$ & 14 & 6 \\
\hline & Dover/FL & $\mathrm{PF}$ & Sanibel & $\mathrm{n} 4$ & 13 & 9 \\
\hline & & $\mathrm{S}$ & Radiance & $\mathrm{n} 11$ & 11 & 7 \\
\hline & Floral City/FL & FR & Albion & n5 & 15 & 9 \\
\hline & & & Festival & $\mathrm{n} 8$ & 13 & 7 \\
\hline & Lexington/SC & K & Camarosa & $\mathrm{n} 10$ & 13 & 2 \\
\hline & & SF & Camarosa & unknown & 13 & 2 \\
\hline & & & & unknown & 13 & 2 \\
\hline & York/SC & $\mathrm{CF}$ & Camarosa & unknown & 15 & 7 \\
\hline & & $\mathrm{JF}$ & Camarosa & $\mathrm{n} 12$ & 15 & 7 \\
\hline \multirow[t]{9}{*}{ 2012-2013 } & Plant City/FL & FF & Festival & unknown & 18 & 9 \\
\hline & & & Radiance & unknown & 13 & 7 \\
\hline & & & & unknown & 13 & 7 \\
\hline & Dover/FL & $\mathrm{PF}$ & Alafia & $\mathrm{n} 4$ & 16 & 9 \\
\hline & & $\mathrm{AF}$ & Festival & $\mathrm{n} 1$ & 13 & 9 \\
\hline & Floral City/FL & FR & Albion & n5 & 15 & 6 \\
\hline & & & Festival & $\mathrm{n} 5$ & 10 & 2 \\
\hline & Lexington/SC & $\mathrm{K}$ & Camarosa & $\mathrm{n} 10$ & 16 & 9 \\
\hline & York/SC & JF & Camarosa & $\mathrm{n} 10$ & 10 & 7 \\
\hline \multirow[t]{4}{*}{ 2013-2014 } & Plant City/FL & $\mathrm{FF}$ & Radiance & n6 & 16 & 11 \\
\hline & & & & $\mathrm{n} 8$ & 16 & 11 \\
\hline & Floral City/FL & FR & Festival & n5 & 17 & 13 \\
\hline & & & Winterstar & $\mathrm{n} 5$ & 18 & 13 \\
\hline
\end{tabular}


irrigated by overhead sprinklers for approximately 10 days. Afterward, plants were irrigated and fertilized through drip irrigation system for the remaining of the season.

Two treatments were compared in the 39 trials, a standard calendarbased fungicide program and a predictive-model-based (StAS) treatment. On each trial, farm managers designated a certain area $(0.5$ to 40 ha) that could be used as the StAS treatment and compared with the grower standard calendar-based treatment. The calendar treatment consisted of weekly applications of either captan or thiram, regardless presence of flowers; however, if in bloom and weather conditions were conducive for disease development, then a single-site fungicide was sprayed instead. The StAS treatment followed the system spray timing recommendations and was sprayed within 24 to $48 \mathrm{~h}$ only after the disease threshold was predicted by the model (alerts). Similarly, captan or thiram was applied in the absence of flowers, whereas a single-site fungicide was used following alerts when the crop was in bloom. No spray was applied within seven days following any application regardless of conditions. Fungicides were tractor-sprayed and the same single-sites were used in both treatments. Thus, the difference between the two treatments was basically the timing and number of sprays applied. Four plots, consisting of the same number of plants within each trial (60 to 300), were designated within each treatment area for data collection. Plots were harvested twice a week from December to March in Florida and from March to May in South Carolina. After each harvest, marketable fruit were counted and weighed to determine yield, and BFR- and AFR-affected fruit was also counted to estimate disease incidence.

Data analysis. Meta-analysis (Borenstein et al. 2009; Madden and Paul 2011) was conducted to quantify the treatment effects on four response variables: BFR incidence; AFR incidence; yield per plant per harvest (Yield, grams); and number of marketable fruit per plant per harvest (Fruit). Response variables for each treatment were identified with the subscripts CAL, for the standard calendar-based application

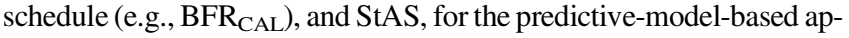
plication schedule $\left(\mathrm{BFR}_{\mathrm{StAS}}\right)$. The effect size for the meta-analysis was the difference in the response variables between the predictor-based treatment and the calendar-based treatment for each trial (e.g., BFRD = $\left.\mathrm{BFR}_{\mathrm{StAS}}-\mathrm{BFR}_{\mathrm{CAL}}\right)$. For the two incidence response variables, this effect size is often known as the risk difference (Borenstein et al. 2009). Analysis was performed on the effect sizes for the full season (results from total harvest), and separately for the early and late parts of the season. Early season refers to those harvests done until 15 January, whereas late season refers to harvests done after that. Because profits are larger for the early harvests (USDA-NASS), quantification for the two parts of the season was performed. Early- and late-season analyses were based only on the Florida data because South Carolina production starts after that period.

A random-effects meta-analytical model was fitted to the effect sizes across the trials using restricted maximum likelihood (REML) (Madden and Paul 2011). The model can be written as:

$$
z_{i}=\xi+u_{i}+\varepsilon_{i}
$$

where $z_{i}$ is the estimated effect size for the $i$-th trial $(i=1, \ldots, 39), \varepsilon_{i}$ is the within-trial (sampling) variability term, $u_{i}$ is the among-trial variability term, and $\xi$ is the expected (mean) effect size for the population of trials (the primary interest of the analysis). $z_{i}$ can refer to difference in incidence of Botrytis fruit rot $\left(\mathrm{BFRD}_{i}\right)$, anthracnose fruit rot $\left(\mathrm{AFRD}_{i}\right)$, yield $\left(\right.$ YieldD $\left._{i}\right)$, or marketable fruit $\left(\right.$ FruitD $\left._{i}\right)$ between the two treatments for each trial. Both $u$ and $\varepsilon$ are random effects with the following distributional assumptions:

$$
\begin{aligned}
& u_{i} \sim N\left(0, \sigma^{2}\right) \\
& \varepsilon_{i} \sim N\left(0, s_{i}^{2}\right)
\end{aligned}
$$

where $\sigma^{2}$ is the among-trial variance, and $s_{i}^{2}$ is the within-trial sampling variance.

Because plots within the commercial fields could not be replicated in this investigation, $s_{i}^{2}$ could not be estimated unambiguously before the meta-analysis. Instead, for disease-incidence effect sizes within trials, we factored $s_{i}^{2}$ into components for an overdispersed binomial distribution (or beta-binomial distribution) and estimated the dispersionparameter component as part of the meta-analysis. For instance, for $\mathrm{BFR}$, the sampling variance is written as:

$$
\begin{aligned}
s_{i}^{2}= & \varphi \cdot\left(\left(\frac{\mathrm{BFR}_{\mathrm{StAS} i} \cdot\left(1-\mathrm{BFR}_{\mathrm{StAS} i}\right)}{N_{i}}\right)\right. \\
& \left.+\left(\frac{\mathrm{BFR}_{\mathrm{CAL} i} \cdot\left(1-\mathrm{BFR}_{\mathrm{CAL} i}\right)}{N_{i}}\right)\right)
\end{aligned}
$$

where $N_{i}$ is the number of plants for a given treatment in a trial, $\varphi$ is the overdispersion parameter (representing variation due to correlation of fruit variables and to sampling and experimental variation within trials), and other terms are as defined above. Equation 2 is based on the number of plants $(N)$ and not the number of fruits because of the assumed high correlation of observations within plants. For yield in weight and number of marketable fruit, we used a simplified version of Equation $1, z_{i}=\xi+u_{i}$, because the within-trial variation cannot be defined.

The meta-analysis involved the estimation of $\xi, \sigma^{2}$, and $\varphi$ (the latter only for incidence-based effect sizes). Based on these parameter estimates, standard errors and confidence intervals were calculated for $\xi$ (estimated mean difference in incidence, or in yield, or number of marketable fruit). The null hypothesis that $\xi$ equaled 0 was tested with a $t$ test based on the parameter estimate and its standard error. The Kenward-Roger degrees of freedom adjustment was used in all analyses; thus, the number of denominator degrees of freedom depended on the magnitude of the estimated variance terms.

The model (Equation 1) was extended to determine if trial-level characteristics (called moderator variables) affected the total-season effect sizes (Madden et al. 2016). Model expansion involved either the addition of a $v_{i j}$ effect term to Equation 1 (where the $j$ subscript refers to the $j$-th level of a categorical moderator variable) or a $\beta X_{i}$ term (where $X$ represents a continuous moderator and $\beta$ is the effect of $X$ ). Trial-level characteristics included year, state, farm, nursery, cultivar, disease incidence in the standard calendar-based schedule (Disease ${ }_{\mathrm{CAL}}$ ), number of fungicide sprays for the StAS treatment (Sprays ${ }_{S t A S}$ ), and difference in number of sprays for the two treatments (SpraysD). The latter three moderator variables (which were treated as continuous covariates in the analysis) are all indicators of the favorability of the environment for disease development, so this analysis allowed us to determine if the efficacy of the predictor-based treatment (relative to the standard calendar-based treatment) is affected by environmental conditions. For instance, because the number of sprays will be high for the StAS treatment when conditions are very favorable for disease development (similar in number to the calendar-based schedule), the difference in number of sprays between the StAS and CAL treatments is negatively related to environmental favorability. $\mathrm{F}$ tests were used to test the null hypothesis that the moderator variable had no effect on the effect size.

\section{Results}

Fungicide applications. The number of fungicide applications for the calendar-based treatment ranged from seven to 18 , with a median of 13, for the 39 trials (Table 1). In comparison, the number of applications for the StAS treatment ranged from two to 13 , with a median of 6 . The number of sprays that were saved by using the predictor ranged from three to 11 , with a median of seven fewer sprays with the predictor compared with the calendar-based schedule.

Botrytis fruit rot. Across the 39 trials, the incidence of BFR for the calendar-based treatment $\left(\mathrm{BFR}_{\mathrm{CAL}}\right)$ ranged from 0.2 to $41 \%$, with a median of $1.9 \%$ (Fig. 1). For the model-based treatment (BFR $\left.{ }_{\mathrm{StAS}}\right)$, incidence ranged from 0.1 to $42.5 \%$, with a median of $2.7 \%$. The difference in incidence (BRFD) per trial ranged from -5.6 to $6.5 \%$, with a median of $0.3 \%$ (Fig. 2). Overlapping distributions of results for the two treatments also were found for the early and late parts of the growing seasons (Figs. 1 and 2), although the overall incidence tended to be higher for the later part of the seasons.

Based on the random-effects meta-analysis (Equation 1), the estimated mean difference in incidence between the predictor and calendar-based treatments $(\hat{\zeta})$ was not significantly different from 0 for early, late, 
or the total season (Table 2). For instance, on a percentage scale, the mean BFRD for total season was $0.26 \%$, with a confidence interval from -0.04 to $0.56 \%$. Thus, there was no evidence for reduction in disease control by following the predictor compared with following a calendar-based spray schedule, even though there was a substantial reduction in number of spray applications. The estimated among-trial variance was 0 for BFR incidence results. This indicates that all the variability in the difference in incidence was accounted for by the within-trial variance (Equation 2) (Madden and Paul 2011).
Anthracnose fruit rot. Incidence of AFR was lower than BFR across the 39 trials (Fig. 1). For the calendar-based treatment for the total season, incidence ranged from 0 to $26.1 \%$, with a median of $0.4 \%$. For the predictor-based treatment, incidence ranged from 0 to $65.4 \%$, with a median of $0.2 \%$. The difference in AFR incidence per trial (AFRD) ranged from -6.7 to $39.3 \%$, with a median of $0 \%$ (Fig. 2). As with BFR, similar distributions of results for the two treatments were found for the early and late parts of the seasons. Note that one large positive outlier, corresponding to a single trial, is omitted
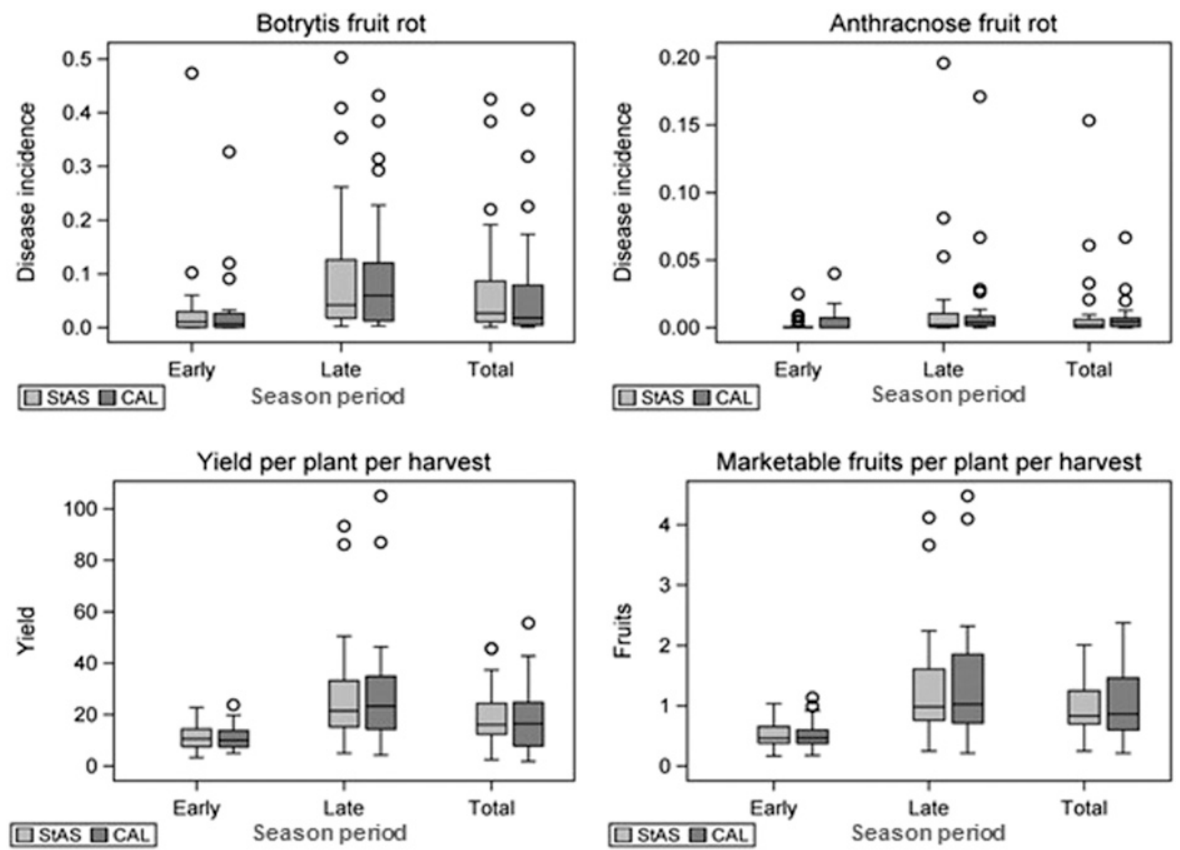

Fig. 1. Box plots of Botrytis fruit rot incidence (BFR), anthracnose fruit rot incidence (AFR), yield per plant per harvest (Yield), and number of marketable fruit per plant per harvest (Fruit) for early season, late season, and total season, for the calendar-based fungicide treatment (CAL) and for the prediction-model-based fungicide treatment (StAS). For AFR, one outlying trial was omitted from the graph for visualization purposes, although all data were used in the analysis.
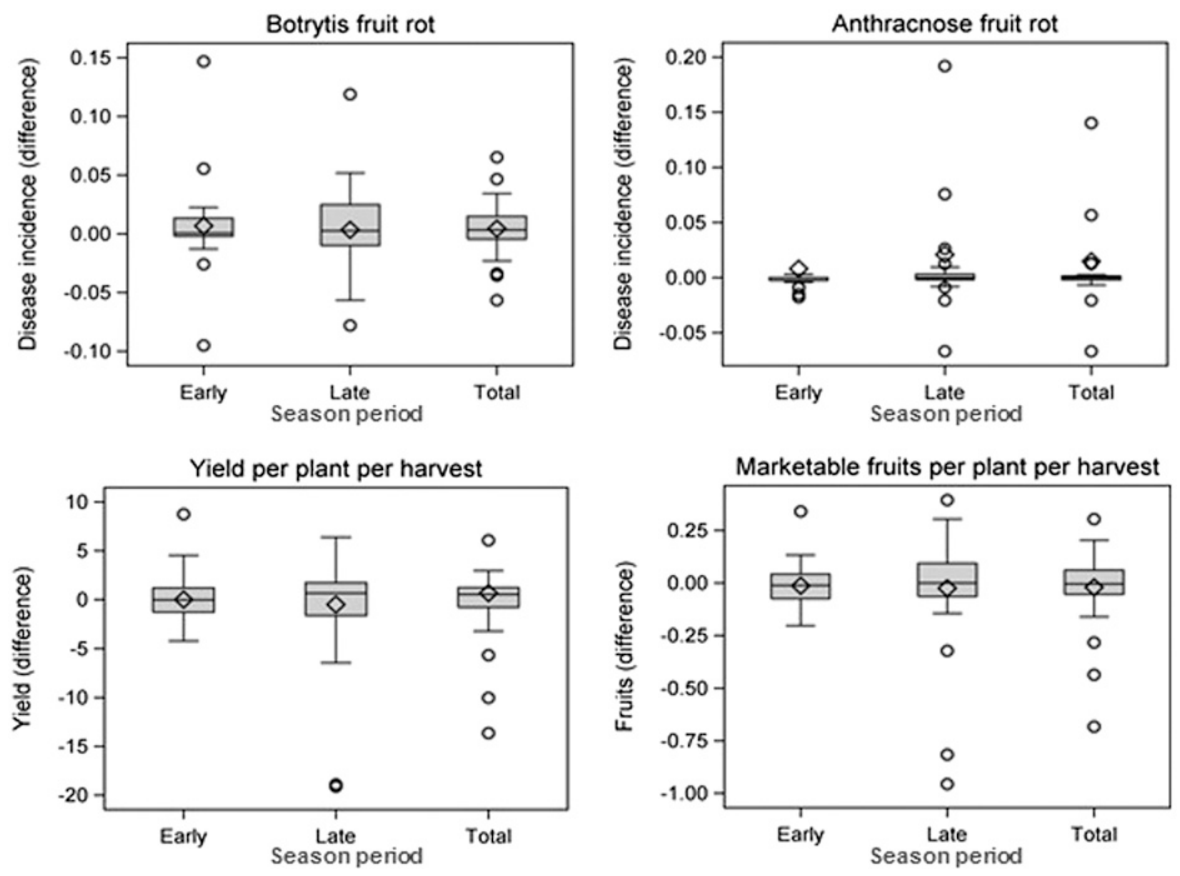

Fig. 2. Box plots of the difference in results between the calendar-based fungicide treatment (CAL) and the prediction-model-based fungicide treatment (StAS) for Botrytis fruit rot incidence (BFRD), anthracnose fruit rot incidence (AFRD), yield per plant per harvest (YieldD), and number of marketable fruit per plant per harvest (FruitD) for early season, late season, and total season. For AFRD and YieldD, one outlier was omitted for visualization purposes. All data were used in the analysis. 
from Figures 1 and 2 for each treatment so that the rest of the data can be visually assessed; all observations (including the outlier) were used in the data analysis.

The meta-analysis showed that the mean difference in incidence between the calendar and predictor treatments $(\hat{\zeta})$ was not significantly different from 0 (Table 2) for total, early, or late season. The mean AFRD for the total season, for example, was $-0.04 \%$. As with BRF, the among-trial variance was estimated at 0 or virtually 0 .

Strawberry yield and number of fruit. Yield per plant per harvest (for the total season) ranged from 1.8 to $55.6 \mathrm{~g}$ for the calendar-based schedule, with a median of $16.5 \mathrm{~g}$; for the predictor-based schedule, yield ranged from 2.4 to $45.8 \mathrm{~g}$, with a median of $16.0 \mathrm{~g}$ (Fig. 1). Yields were somewhat higher for the late season compared with the early season, although the distributions of results overlapped fully for the two treatments. The difference in yield between the two treatments (YieldD) ranged from -13.7 to $34.0 \mathrm{~g}$, with a median of $0.6 \mathrm{~g}$. One large positive outlier for YieldD was omitted from Figure 2 for the total-season results only, to better visualize the results from all the other trials; all observations were used in the analysis.

The meta-analysis indicated that the mean yield difference between the two treatments $(\hat{\zeta})$ was not significantly different from 0 for early, late, or total seasons (Table 2). For instance, the mean YieldD was 0.7, 0.01 , and $-0.5 \mathrm{~g}$ for the total, early, and late seasons, respectively.

The number of marketable fruit per plant per harvest (for the total season) ranged from 0.2 to 2.4 for the calendar-based treatment, and from 0.2 to 2.0 for the predictor-based treatment (Fig. 1). The medians were 0.86 and 0.83 , respectively, for these two treatments across the trials. As with yield, the number of marketable fruit were generally greater for late compared with early seasons, although results overlapped greatly for the two treatments (Fig. 1). The difference in number of marketable fruit based on total seasons (FruitD) ranged from -0.7 to 0.3 (Fig. 2), with a median of 0 .

Mean difference in number of marketable fruit for the two treatments $(\hat{\zeta})$ was not significantly different from 0 for the total, early, and late seasons (Table 2). For example, the mean for the total seasons was -0.2 , with a confidence interval of -0.088 and 0.046 .

Moderator variable analysis. There was no significant effect $(P>0.05)$ of disease incidence for the calendar-based treatment, number of sprays applied based on the predictor, or difference in number of sprays between the two treatments on either the BFRD or AFRD (differences in incidence between the two treatments for the total seasons) (Table 3).

Year had a significant effect on BFRD, but not on AFRD (Table 3). Based on multiple comparisons of the means for the different years (data not shown), the 2012/13 season had a higher BFRD compared with the 2010/2011 season; that is, the predictor performance was not as effective in 2012/2013 relative to 2010/2011. The other year means that were intermediate between these two and not significantly different from either one.

BFRD and AFRD were significant affected by cultivar $(P=0.039$ and $P=0.031$, respectively) (Table 3 ). According to the multiple comparison of the means of the different cultivars, 'Alafia' had the

Table 2. Fit of a univariate meta-analytical model (Equation $1^{\text {a }}$ ) to four effect sizes based on differences in results between calendar-based fungicide applications and predictor-model-based fungicide applications: incidence of Botrytis fruit rot (BFRD), incidence of anthracnose fruit rot (AFRD), yield per plant per harvest (YieldD), and number of marketable fruit per plant per harvest (FruitsD)

\begin{tabular}{|c|c|c|c|c|c|c|c|c|}
\hline Effect size $^{\mathbf{b}}$ & Period $^{c}$ & Mean $(\xi)$ & SE & df & $P$ & $\sigma^{2}$ & 95\% Conf. int. & $\varphi$ \\
\hline \multirow[t]{3}{*}{ BFRD } & Total & 0.00263 & 0.00149 & 38 & 0.0860 & $\mathbf{0}$ & $-0.00039 \leftrightarrow 0.00565$ & 0.852 \\
\hline & Early & 0.00062 & 0.00121 & 27 & 0.6101 & 0 & $-0.00185 \leftrightarrow 0.00310$ & 1.174 \\
\hline & Late & 0.00161 & 0.00317 & 30 & 0.6155 & 0 & $-0.00487 \leftrightarrow 0.00809$ & 1.383 \\
\hline \multirow[t]{3}{*}{ AFRD } & Total & -0.00039 & 0.00095 & 33 & 0.6868 & $\mathbf{0}$ & $-0.00023 \leftrightarrow 0.00154$ & 1.393 \\
\hline & Early & -0.00187 & 0.00120 & 27 & 0.1310 & $10^{-6}$ & $-0.00433 \leftrightarrow 0.00059$ & 0.702 \\
\hline & Late & -0.00026 & 0.00123 & 30 & 0.8350 & 0 & $-0.00277 \leftrightarrow 0.00225$ & 2.158 \\
\hline \multirow[t]{3}{*}{ YieldD } & Total & 0.6692 & 1.0610 & 37 & 0.5321 & 42.78 & $-1.4806 \leftrightarrow 2.8190$ & - \\
\hline & Early & 0.01092 & 0.5082 & 27 & 0.9830 & 7.23 & $-1.0319 \leftrightarrow 1.0537$ & - \\
\hline & Late & -0.4945 & 1.0297 & 30 & 0.6345 & 32.87 & $-2.5976 \leftrightarrow 1.6085$ & - \\
\hline \multirow[t]{3}{*}{ FruitD } & Total & -0.0209 & 0.03284 & 30 & 0.5299 & $\mathbf{0 . 0 3 3}$ & $-0.0879 \leftrightarrow \mathbf{0 . 0 4 6 2}$ & - \\
\hline & Early & -0.0129 & 0.02135 & 27 & 0.5505 & 0.013 & $-0.0567 \leftrightarrow 0.0309$ & - \\
\hline & Late & -0.0251 & 0.04857 & 30 & 0.6096 & 0.073 & $-0.1243 \leftrightarrow 0.0741$ & - \\
\hline
\end{tabular}

${ }^{a}$ With $\sigma^{2}$ for the between-trial variance and $\varphi$ within-trial variability (overdispersion) parameter.

${ }^{\mathrm{b}} \mathrm{BFRD}$ and $\mathrm{AFRD}=$ difference of botrytis and anthracnose fruit rot incidence between the predictor-model-based and the calendar-based treatment, respectively YieldD $=$ difference of yield per plant per harvest between the predictor-model-based and the calendar-based treatment. FruitD $=$ difference of number of marketable fruit per plant per harvest between the predictor-model-based and the calendar-based treatment.

${ }^{\mathrm{c}}$ Early refers to harvests done until 15 January, whereas Late refers to harvest done after that. Total represents all the harvests done in a trial.

Table 3. Effects of moderator variables on difference in disease incidence and yield between the calendar-based treatment and the predictor-based treatment for Botrytis fruit rot (BFRD), anthracnose fruit rot (AFRD), marketable yield (YieldD), and number of marketable fruit (fruitD)

\begin{tabular}{|c|c|c|c|c|c|c|c|c|c|c|c|c|}
\hline \multirow[b]{2}{*}{ Moderator variable ${ }^{\mathbf{a}}$} & \multicolumn{3}{|c|}{ Botrytis (BFRD) $)^{\mathbf{b}}$} & \multicolumn{3}{|c|}{ Anthracnose (AFRD) ${ }^{\mathrm{c}}$} & \multicolumn{3}{|c|}{ Marketable yield (YieldD) ${ }^{\mathbf{d}}$} & \multicolumn{3}{|c|}{ Marketable fruit (FruitD) ${ }^{\mathrm{e}}$} \\
\hline & $d f_{N}, d f_{D}$ & $\mathbf{F}$ & $P$ & $d f_{N}, d f_{D}$ & $\mathbf{F}$ & $P$ & $\mathbf{d f _ { N }}, \mathbf{d f}_{\mathrm{D}}$ & $\mathbf{F}$ & $P$ & $d f_{N}, d f_{D}$ & $\mathbf{F}$ & $P$ \\
\hline Disease $_{\mathrm{CAL}}$ & $1,35.9$ & 0.7 & 0.408 & 1,32 & 1.07 & 0.308 & - & - & - & - & - & - \\
\hline Year & $4,34.0$ & 3.41 & 0.019 & 4,29 & 0.43 & 0.785 & - & - & - & - & - & - \\
\hline State & $1,14.4$ & 0.8 & 0.387 & 1,32 & 0.00 & 0.993 & - & - & - & - & - & - \\
\hline Location & $10,16.7$ & 1.43 & 0.249 & 8,25 & 0.15 & 0.995 & - & - & - & - & - & - \\
\hline Cultivar & $7,20.2$ & 2.69 & 0.039 & 6,21 & 2.91 & 0.031 & 7,29 & 2.77 & 0.025 & 6,21 & 4.53 & 0.004 \\
\hline SpraysD & 1,31 & 0.43 & 0.516 & 1,26 & 0.28 & 0.603 & 1,35 & 0.72 & 0.402 & 1,29 & 2.99 & 0.094 \\
\hline Sprays $_{\text {StAS }}$ & 1,31 & 0.18 & 0.678 & 1,26 & 0.05 & 0.824 & 1,35 & 0.18 & 0.675 & 1,29 & 0.19 & 0.666 \\
\hline
\end{tabular}

${ }^{a}$ Disease ${ }_{\mathrm{CAL}}=$ disease incidence (either BFR or AFR, depending on the effect size) for the calendar-based treatment. Year $=$ year of the trial. State $=$ state where trial was conducted $(\mathrm{FL}$ or SC). Location = individual farm. Nursery: individual nursery were transplants were produced; Cultivar $=$ indicator of the cultivar

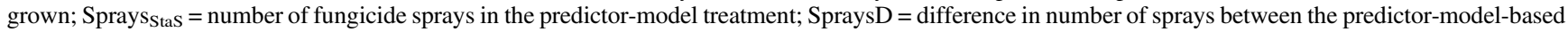
and the calendar-based treatment.

${ }^{\mathrm{b}} \mathrm{BFRD}=$ difference of botrytis fruit rot incidence between the predictor-model-based and the calendar-based treatment.

${ }^{c} \mathrm{AFRD}=$ difference of anthracnose fruit rot incidence between the predictor-model-based and the calendar-based treatment.

${ }^{\mathrm{d}}$ YieldD $=$ difference of yield per plant per harvest between the predictor-model-based and the calendar-based treatment.

${ }^{\mathrm{e}}$ FruitD $=$ difference of number of marketable fruit per plant per harvest between the predictor-model-based and the calendar-based treatment. 
highest negative BFRD, meaning that the predictor-based treatment had lower BFR incidence than the calendar-based treatment for this cultivar. 'Treasure' presented the highest AFRD, with a positive difference. Thus, this cultivar had higher AFR incidence in the predictor-based treatment than in the calendar-based treatment (data not shown).

YieldD and FruitD were also significant affected by cultivar $(P=$ 0.025 and $P=0.004$, respectively) (Table 3). 'Treasure' had lower YieldD and FruitD compared with all the other cultivars; that is, the predictor-based treatment did not produce the same level of yield or marketable fruit as the calendar-based treatment for this cultivar (data not shown).

The difference in number of sprays between the predictor-modelbased and the calendar-based treatment (SpraysD), and the number of sprays applied based on the predictor $\left(\right.$ Sprays $\left._{S t a S}\right)$, had no significant effect over YieldD and FruitD (Table 3).

\section{Discussion}

MacKenzie and Peres (2012a; 2012b) showed that the two most important fruit rot diseases of strawberries in the southeastern United States (Botrytis fruit rot [BFR] and anthracnose fruit rot [AFR]) can be controlled by fungicides in small experimental plots when spray applications are timed according to disease index thresholds based on the models in Bulger et al. (1987) and Wilson et al. (1990). Partly inspired by initial field success with the predictor models (MacKenzie and Peres 2012a; 2012b), the StAS system was released in 2010 for commercial use (Pavan et al. 2011). Grower acceptance, however, depended on an assessment of the effectiveness of the system when used on a commercial-field scale over a range of environmental and crop conditions, which can be determined by considering disease and yield outcomes from multiple fields and multiple years. Commercial field trials with two treatments, corresponding to calendar-based and StASbased fungicide applications, were thus conducted to quantify the effectiveness of the system.

The meta-analysis of the outcomes of 39 field trials shows that the mean difference in disease incidence for both BFR and AFR, number of marketable fruit, and yield between the calendar and predictor treatments $(\hat{\zeta})$ were not significantly different from 0 in any time period (early, late, and total season) (Table 2). This confirms the smallplot results of MacKenzie and Peres (2012a; 2012b). Results for the early season in commercial fields are especially important because of the higher returns during this time (USDA Agricultural Marketing Service). Thus, no loss in disease control and yield were observed, even with a consistent reduction in the number of fungicide applications compared with the calendar-based treatment. A median of seven fewer applications per growing season were made with the predictorbased treatment compared with the calendar-based approach; about a $50 \%$ reduction in the number of sprays. These results show that using the StAS not only reduces the need for fungicide treatments for fruit rots of strawberry, but provides a degree of disease control equal to that obtained with a calendar-based treatment under a wide range of environmental and cropping (e.g., location, nursery source) conditions. Besides the efficacy in managing fruit rot with reduced fungicide treatments, the StAS has been shown to have economic advantages over the calendarbased program based on a theoretical investigation. Vorotnikova et al. (2014) simulated the distribution of 10-year net present value of profits for the StAS- and calendar-based treatments. They used yield data from six-year field trials conducted at the Gulf Coast Research and Education Center-UF comparing the StAS to the calendar-based treatment, combined with historical state-level data (weather and price) as input to a Monte Carlo stochastic simulation. Similarly to this study, the authors found that the StAS decreases fungicide use (47\% on average for anthracnose and $49 \%$ for Botrytis) in the simulation model, while increasing the average profit by $41.6 \%$ for AFR and $16.8 \%$ for BFR. Vorotnikova et al. (2014) assumed that yields are slightly reduced when following the predictor, although our new results from commercial fields show no evidence of a reduction. Thus, we expect that estimated profitability would be even higher than their simulation study.

There was considerable variability in the three moderator variables that represent favorability of the environment for disease development
(Disease ${ }_{\mathrm{CAL}}$, Sprays $_{\mathrm{StAS}}$, and SpraysD), but none of these variables significantly affected either BFRD or AFRD (Table 3). Sprays ${ }_{S t A S}$ and SpraysD also did not affect the yield effect sizes. Thus, there was no evidence that the efficacy of the predictor for controlling the two fruit rot diseases was influenced by the favorability of conditions for disease development. Moreover, neither state nor farm within state affected these effect sizes (Table 3). These support the conclusion that, overall, the system is reliable to use in the southeastern United States for most strawberry cultivars regardless of the specific location and environmental conditions of the area.

The moderate variable "cultivar" did have a significant effect on AFRD, BFRD, YieldD, and FruitD (Table 3). Most cultivars had very similar results, but the cultivar Treasure had a significantly higher incidence of AFR, lower yield, and lower numbers of marketable fruit in the predictor-based treatment than in the calendar-based treatment. Treasure is a cultivar highly susceptible to AFR that is no longer grown in the area (Seijo et al. 2008; Seijo et al. 2014). This suggests that when using a cultivar highly susceptible to AFR, such as Treasure, the StAS might not be as effective in managing the disease as the calendar-based program. In contrast, for the BFRD effect size, the cultivar Alafia had a significantly lower incidence with the predictor-based treatment than with the calendar-based treatment. This may be related to plants of this cultivar being free of quiescent infections or the confounding of this cultivar effect with other (unmeasured) factors that affect fungicide efficacy (each cultivar was only grown at some farms in some years).

Decision-support systems (DSSs) applied to agriculture are generally computer-based, interactive systems that aid growers' and consultants' decision-making process (Gent et al. 2013). The systems are designed to reduce the time and resources necessary to analyze complex problems under uncertain situations. StAS is one such DSS that implements the forecasting models for BFR and AFR (Pavan et al. 2011). The reduction in fungicide applications, however, is not the only goal of DSSs. Avoidance of risks related to disease outbreaks, integrated disease management, increased yields and profit are also desirable goals for the implementation of these systems (Gent et al. 2013; Shtienberg 2013). DSSs may vary in complexity, being made up of simple databases, spreadsheets, simulation models, geographic information systems (GIS), or more complex combinations of tools (Shtienberg, 2013). Ideally, if validated, DSSs offer significant or sufficient benefits over current alternatives to justify the addition of extra complexity to the decision-making process (Gent et al. 2013).

Although forecasting systems, whether incorporated or not into explicit DSSs, have been employed in plant pathology for decades (Campbell and Madden 1990; De Wolf and Isard 2007), development and implementation of DSSs for the purpose of disease prediction and management have grown substantially in recent years due to integration of accurate disease models with advances in information technology, Internet delivery of information, meteorological models, GIS, and accessible site-specific weather forecasts (Gent et al. 2013). Magarey et al. (2002) have discussed the importance of user-friendly systems for high DSS acceptance by the potential users. The DSS should not take time from the busy schedule of the growers. The system needs to be "self-fed" with information, requiring little or no user data input. For instance, weather data should be downloaded and updated automatically from weather stations into the system without the need for grower involvement. The user's platform with the disease forecasts and fungicide recommendations should be colorcoded and self-explanatory, and be understandable within seconds. In case users want more detailed information and complexity, it can also be found in the system. These characteristics are all addressed by the StAS, as described by Pavan et al. (2011).

Even though the number of DSSs has been growing, many disease predictor systems have not been widely used or adopted by growers (Gent et al. 2013; McRoberts et al. 2011; Shtienberg 2013). In addition to the features discussed above, to be successful and adopted by users, a DSS (or any forecasting system) needs to be easily incorporated into the current decision-making and crop-production processes, and be economically beneficial (Gent et al. 2013). According to a survey of strawberry producers conducted in Florida by Borisova 
et al. (2014), approximately $50 \%$ of the survey respondents were subscribed to the system and receive text messages and/or e-mail from the StAS. This number corresponds to direct users, hence the actual percentage of growers following the StAS recommendations might be greater than that reported. Surveys based on the number of direct users do not consider growers that are not subscribed to the predictor system but still follow its recommendations indirectly through people in their decision networks (i.e., consultants, neighbors, and extension agents); this process can be referred to as indirect adoption (Gent et al. 2013).

Many reasons may be proposed to explain the adoption success of the StAS in Florida in recent years. The accuracy of the system in predicting the need for fungicide applications, and the management of both diseases with reduced fungicide applications have been demonstrated in this study. The economic advantage over the calendarbased treatment has also been shown theoretically by Vorotnikova et al. (2014), as briefly discussed above. However, observation of the commercial-field trials by growers as the studies were being conducted, coupled with the summary of results in extension presentations, might have been the greatest contributors to the successful adoption of the StAS. Strawberry is a high-value crop (USDA Agricultural Marketing Service), in which fruit quality is essential for high prices, hence growers are generally unwilling to accept the risk of BFR and AFR outbreaks if the StAS produces inaccurate predictions. This is consistent with the concept of Regret discussed by McRoberts et al. (2011). Performing these trials in commercial fields over different seasons helped to convince growers that the recommendations from the StAS were timely and accurate, resulting in effective disease control. Finally, recent reports of multifungicide resistance to the BFR and AFR pathogens have encouraged growers to adopt reducedfungicide programs (Amiri et al. 2013; Fernández-Ortuño et al. 2015).

Many DSSs, even though accurate and economically efficient, lose users over time since DSSs are also learning tools. The information provided by some DSSs may be incorporated into the user's expertise, and hence the DSS no longer needs to be explicitly accessed. Its recommendations have become the standard management for the pathosystem. However, DSSs developed to forecast or manage diseases that occur sporadically, or where the risk varies greatly during or between growing seasons, especially in response to weather, are less easily replaced by growers' expertise and experience with the system (Gent et al. 2013). Thus, it appears that the StAS is not easily replaced by grower expertise and learning, especially since the disease risk does vary substantially (as quantified by the difference in spray applications between the two treatments [Table 1]), and since the DSS is continually updated. Example of updates are the fungicide recommendations (e.g., FRAC codes or mixtures to use) based on field trials conducted in commercial farms in Florida (Cordova et al. 2017), and the release of new products, such as the StAS mobile app, which allows users to access the system on their smart phones on the field (Fraisse et al. 2015). The StAS and other similar DDSs can provide material to enable well-informed decisions and maximize the efficiency of crop protection strategies without adding extra complexity to the decision-making process.

\section{Acknowledgment}

This research was supported by a USDA-NIFA fund under a project No.2010-51181-21113. We thank all staff, students, and interns for field assistance collecting data from these trials over the years.

\section{Literature Cited}

Amiri, A., Heath, S. M., and Peres, N. A. 2013. Phenotypic characterization of multifungicide resistance in Botrytis cinerea isolates from strawberry fields in Florida. Plant Dis. 97:393-401.

Borenstein, M., Hedges, L., Higgins, J., and Rothstein, H. 2009. Introduction to Meta-analysis. John Wiley \& Sons, Chichester, UK.

Borisova, T., Guan, Z., Vorotnikova, E., Peres, N., and VanSickle, J. 2014. Florida strawberry producers' experiences with anthracose and Botrytis fruit rot, and producers' use of the strawberry advisory system. EDIS Food and Resource Econ. Dept., UF/IFAS Ext., Gainesville, FL.

Bulger, M., Ellis, M., and Madden, L. 1987. Influence of temperature and wetness duration on infection of strawberry flowers by Botrytis cinerea and disease incidence of fruit originating from infected flowers. Phytopathology 77:12251230.

Campbell, C. L., and Madden, L. V. 1990. Introduction to Plant Disease Epidemiology. John Wiley \& Sons, New York.

Chandler, C. K., Mertely, J. C., and Peres, N. A. 2006. Resistance of selected strawberry cultivars to anthracnose fruit rot and botrytis fruit rots. Acta Hortic. 708:123-126.

Cordova, L. G., Amiri, A., and Peres, N. A. 2017. Effectiveness of fungicide treatments following the Strawberry Advisory System for control of Botrytis fruit rot in Florida. Crop Prot. 100:163-167.

Dalla Lana, F., Ziegelmann, P. K., Maia, A. H. N., Godoy, C. V., and Del Ponte, E. M. 2015. Meta-analysis of the relationship between crop yield and soybean rust severity. Phytopathology 105:307-315.

De Wolf, E. D., and Isard, S. A. 2007. Disease cycle approach to plant disease prediction. Annu. Rev. Phytopathol. 45:203-220.

Ellis, M. A., and Grove, G. G. 1982. Fruit rots cause losses in Ohio strawberries. Ohio Rep. Res. Dev. 67:3-4.

Fernández-Ortuño, D., Grabke, A., Li, X., and Schnabel, G. 2015. Independent emergence of resistance to seven chemical classes of fungicides in Botrytis cinerea. Phytopathology 105:424-432.

Fraisse, C., Breuer, N., Zierden, D., Bellow, J., Paz, J., Cabrera, V., Garcia, A. G., Ingram, K., Hatch, U., and Hoogenboom, G. 2006. AgClimate: A climate forecast information system for agricultural risk management in the southeastern USA. Comput. Electron. Agric. 53:13-27.

Fraisse, C. W., Peres, N. A., and Andreis, J. H. 2015. Smart strawberry advisory system for mobile devices. AE516. UF-IFAS, Gainesville, FL. http://edis.ifas.ufl edu/AE516

Gent, D. H., Mahaffee, W. F., McRoberts, N., and Pfender, W. F. 2013. The use and role of predictive systems in disease management. Annu. Rev. Phytopathol. 51:267-289.

Howard, C. M., Maas, J. L., Chandler, C. K., and Albregts, E. E. 1992. Anthracnose of strawberry caused by the Colletotrichum complex in Florida Plant Dis. 76:976-981.

Komatsu, T., and Kondo, N. 2015. Efficacy of a copper-based bactericide in controlling bacterial blight of grapevines caused by Xylophilus ampelinus. J. Gen. Plant Pathol. 81:409-414.

Legard, D. E., MacKenzie, S. J., Mertely, J. C., Chandler, C. K., and Peres, N. A. 2005. Development of a reduced use fungicide program for control of Botrytis fruit rot on annual winter strawberry. Plant Dis. 89: 1353-1358.

Legard, D. E., Xiao, C. L., Mertely, J. C., and Chandler, C. K. 2001. Management of Botrytis fruit rot in annual winter strawberry using captan, thiram, and iprodione. Plant Dis. 85:31-39.

MacKenzie, S. J., and Peres, N. A. 2012a. Use of leaf wetness and temperature to time fungicide applications to control anthracnose fruit rot of strawberry in Florida. Plant Dis. 96:522-528.

MacKenzie, S. J., and Peres, N. A. 2012b. Use of leaf wetness and temperature to time fungicide applications to control Botrytis fruit rot of strawberry in Florida Plant Dis. 96:529-536.

Madden, L. V., and Paul, P. A. 2011. Meta-analysis for evidence synthesis in plan pathology: An overview. Phytopathology 101:16-30.

Madden, L. V., Piepho, H. P., and Paul, P. A. 2016. Statistical models and methods for network meta-analysis. Phytopathology 106:792-806.

Magarey, R., Travis, J., Russo, J., Seem, R., and Magarey, P. 2002. Decision support systems: Quenching the thirst. Plant Dis. 86:4-14.

McRoberts, N., Hall, C., Madden, L., and Hughes, G. 2011. Perceptions of disease risk: From social construction of subjective judgments to rational decision making. Phytopathology 101:654-665.

Mertely, J. C., MacKenzie, S. J., and Legard, D. E. 2002. Timing of fungicide applications for Botrytis cinerea based on development stage of strawberry flowers and fruit. Plant Dis. 86:1019-1024.

Mertely, J. C., Seijo, T. E., MacKenzie, S. J., Moyer, C., and Peres, N. A. 2009 Effect of timing of preharvest fungicide applications on postharvest Botrytis fruit rot of annual strawberries in Florida. Plant Health Prog. doi:10.1094/ PHP-2009-0921-01-RS

Ngugi, H. K., Lehman, B. L., and Madden, L. V. 2011. Multiple treatment metaanalysis of products evaluated for control of fire blight in the eastern United States. Phytopathology 101:512-522.

Paul, P., Lipps, P., Hershman, D., McMullen, M., Draper, M., and Madden, L. 2008. Efficacy of triazole-based fungicides for Fusarium head blight and deoxynivalenol control in wheat: A multivariate meta-analysis. Phytopathology 98:999-1011.

Paul, P. A., Lipps, P. E., and Madden, L. V. 2005. Relationship between visual estimates of Fusarium head blight intensity and deoxynivalenol accumulation in harvested wheat grain: A meta-analysis. Phytopathology 95:1225-1236.

Paul, P. A., Madden, L. V., Bradley, C. A., Robertson, A. E., Munkvold, G. P., Shaner, G., Wise, K. A., Malvick, D. K., Allen, T. W., Grybauskas, A., Vincelli, P., and Esker, P. 2011. Meta-analysis of yield response of hybrid field corn to foliar fungicides in the U.S. corn belt. Phytopathology 101: 1122-1132.

Pavan, W., Fraisse, C. W., and Peres, N. A. 2011. Development of a web-based disease forecasting system for strawberries. Comput. Electron. Agric. 75: 169-175. 
Peres, N. A., Seijo, T. E., and Turechek, W. W. 2010. Pre- and post-inoculation activity of a protectant and a systemic fungicide for control of anthracnose fruit rot of strawberry under different wetness durations. Crop Prot. 29:1105-1110.

Peres, N. A., Timmer, L. W., Adaskaveg, J. E., and Correll, J. C. 2005. Life styles of Colletotrichum acutatum. Plant Dis. 89:784-796.

Piepho, H. P., Williams, E. R., and Madden, L. V. 2012. The use of two-way linear mixed models in multitreatment meta-analysis. Biometrics 68:1269-1277.

Salam, K. P., Thomas, G. J., Beard, C., Loughman, R., MacLeod, W. J., and Salam, M. U. 2013. Application of meta-analysis in plant pathology: A case study examining the impact of fungicides on wheat yield loss from the yellow spot-Septoria nodorum blotch disease complex in Western Australia. Food Secur. 5:319-325.

Scherm, H., Thomas, C., Garrett, K., and Olsen, J. 2014. Meta-analysis and other approaches for synthesizing structured and unstructured data in plant pathology. Annu. Rev. Phytopathol. 52:453-476.

Seijo, T., Mertely, J., Whitaker, V., and Peres, N. 2014. Evaluation of strawberry cultivars and advanced selections for resistance to anthracnose and Botrytis fruit rots, 2012-2013. Plant Dis. Manag. Rep. 8:SMF029.
Seijo, T. E., Chandler, C. K., Mertely, J. C., Moyer, C., and Peres, N. A. 2008. Resistance of strawberry cultivars and advanced selections to anthracnose and Botrytis fruit rots. Proc. Fla. State Hortic. Soc. 121:246-248.

Shtienberg, D. 2013. Will decision-support systems be widely used for the management of plant diseases? Annu. Rev. Phytopathol. 51:1-16.

Turechek, W. W., Peres, N. A., and Werner, N. A. 2006. Pre- and post-infection activity of pyraclostrobin for control of anthracnose fruit rot of strawberry caused by Colletotrichum acutatum. Plant Dis. 90:862-868.

Vorotnikova, E., Borisova, T., and VanSickle, J. J. 2014. Evaluation of the profitability of a new precision fungicide application system for strawberry production. Agric. Syst. 130:77-88.

Willyerd, K., Li, C., Madden, L., Bradley, C., Bergstrom, G., Sweets, L. McMullen, M., Ransom, J., Grybauskas, A., and Osborne, L. 2012. Efficacy and stability of integrating fungicide and cultivar resistance to manage Fusarium head blight and deoxynivalenol in wheat. Plant Dis. 96:957-967.

Wilson, L. L., Madden, L. V., and Ellis, M. A. 1990. Influence of temperature and wetness duration on infection of immature and mature strawberry fruit by Colletotrichum acutatum. Phytopathology 80:111-116. 